\title{
Efeito da adição do ácido linoleico conjugado no cultivo in vitro de embriões F1 Holandês x Zebu na sobrevivência pós-vitrificação
}

\author{
[Effect of conjugated linoleic acid addition in in vitro culture medium in F1 Holstein X Zebu embryo \\ survival post vitrification]
}

\author{
A.C. Leite, V.B. Andrade, E.B.M. Silva, A.M. Borges
}

Universidade Federal de Minas Gerais - UFMG - Belo Horizonte, MG

\begin{abstract}
RESUMO
Avaliou-se o efeito da adição do ácido linoleico conjugado (CLA) ao meio de cultivo in vitro na viabilidade pós-vitrificação de embriões F1 Holandês x Zebu. Foram utilizados três meios de cultivo: controle ( $n=340$ oócitos): meio SOF e soro fetal bovino (SFB), sem o CLA; SFB+CLA ( $n=359$ oócitos): meio SOF, SFB e CLA; CLA ( $n=339$ oócitos): meio SOF e CLA, sem o SFB. Todos os blastocistos produzidos foram submetidos à vitrificação, pelo método de Open Pulled Straw. Quinze blastocistos de cada tratamento foram fixados para quantificação lipídica por coloração com Sudan Black B. Para avaliar a viabilidade embrionária, foi observada a capacidade de reexpansão e eclosão pós-aquecimento dos embriões (controle=27; $\mathrm{SFB}+\mathrm{CLA}=30 ; \mathrm{CLA}=17$ ). Foram realizadas transferências em um ou dois embriões por receptora para avaliação da sobrevivência in vivo: T1 [receptoras que receberam um blastocisto $(n=17$ embriões, sendo controle $=5, \mathrm{SFB}+\mathrm{CLA}=6$ e CLA=6)]; T2 [receptoras que receberam dois blastocistos, ( $n=54$ embriões, sendo controle $=18, \mathrm{SFB}+\mathrm{CLA}=14$ e CLA=22)]. Não houve diferença nas taxas de clivagem $(62,1 \% ; 74,0 \% ; 74,0 \%$ para controle; SFB+CLA; CLA, respectivamente), produção de blastocistos em relação aos clivados $(59,7 \% ; 47,7 \% ; 38,3 \%$ para controle; SFB+CLA; CLA, respectivamente) e produção de blastocistos em relação ao total de oócitos $(37,1 \% ; 35,4 \% ; 28,3 \%$ para controle; SFB+CLA; CLA, respectivamente $(\mathrm{P}>0,05)$. Houve diminuição de gotículas lipídicas nos embriões cultivados em meio suplementado com CLA em relação aos embriões cultivados na presença do SFB e na ausência do CLA $(\mathrm{P}<0,05)$. A taxa de reexpansão foi maior no grupo controle $(70,4 \%) \mathrm{em}$ relação ao CLA $(47,1 \%)$ e menor no grupo SFB+CLA $(43,3 \%)(\mathrm{P}<0,05)$. O CLA foi eficaz em reduzir a deposição de lipídeos intracitoplasmáticos nas células embrionárias, porém não houve diferença de viabilidade após a desvitrificação dos embriões.
\end{abstract}

Palavras-chave: ácido linoleico conjugado, ácido linoleico conjugado trans-10, cis-12, CLA, criopreservação de embriões, vitrificação de embriões

\begin{abstract}
The effect of adding conjugated linoleic acid (CLA) to the culture media on the viability after cryopreservation of F1 Holstein X Zebu embryos was evaluated. Three different culture media were tested: control $(n=340$ oocytes): SOF medium and fetal bovine serum (FBS) without the CLA; FBS + CLA ( $n=359$ oocytes): SOF, FBS and CLA; CLA ( $n=339$ oocytes): SOF and CLA without the FBS. The produced blastocysts were subjected to vitrification, by the Open Pulled Straw method. Fifteen blastocysts per treatment were fixed for lipid quantification by staining with Sudan Black B. Embryo re-expansion and hatching capability were used to assess viability (control $=27 ; F B S+C L A=30 ; C L A=17)$. Transfers of one or two embryos to recipients were performed to evaluate in vivo survival: $T 1$ [recipients that received one blastocyst ( $n=17$ embryos, Control=5, FBS $+C L A=6$ and $C L A=6)$ ]; $T 2$ [recipients that received two blastocysts ( $n=54$ embryos, Control=18, FBS $+C L A=14$ and $C L A=22)]$. There was no difference in cleavage rate $(62.1 \% ; 74 \% ; 74 \%$ for Control; FBS + CLA, CLA, respectively), blastocyst production in relation to the cleaved structures (59.7\%; 47.7\%; 38 3\% for Control; FBS + CLA, CLA, respectively) and blastocyst production relative to the total
\end{abstract}

Recebido em 5 de julho de 2016

Aceito em 3 de dezembro de 2016

E-mail: k_rolleite@yahoo.com.br 
oocytes (37.1\%, 35.4\%, 28.3\% for Control; FBS + CLA, CLA, respectively) between treatments $(P>0.05) . A$ reduction of lipid droplets was observed in embryos cultured in medium supplemented with CLA compared to embryos cultured in the FCS in the absence and presence of CLA $(P<0.05)$. The reexpansion rate was higher in the Control group (70.4\%) compared to the CLA (47.1\%) and lowest for FBS+CLA (43.3\%) $(P<0.05)$. The hatching rates were similar among treatments, 42.1\%; 23.1\%; 25\% for control; SFB + CLA; CLA respectively $(P>0.05)$. Only one pregnancy was observed in early and confirmatory diagnosis, as the result of a Control group embryo transfer. Although embryos cultured with CLA have shown smaller intracytoplasmic lipid content, no difference was observed in viability following vitrification between treatments.

Keywords: conjugated linoleic acid, conjugated linoleic acid trans-10, cis-12, CLA, embryo cryopreservation, embryo vitrification

\section{INTRODUÇÃO}

Atualmente, o maior obstáculo para disseminação da produção in vitro de embriões bovinos (PIVE) é a baixa taxa de sobrevivência dos embriões ao descongelamento. $\mathrm{O}$ alto teor lipídico citoplasmático implica reduções na qualidade embrionária e na resistência ao congelamento deles (Pereira et al., 2007) (Mezzalira e Vieira, 2006). A criopreservação de embriões e gametas possibilita a manutenção da viabilidade de embriões excedentes e a utilização do estro natural de receptoras, que resulta em taxas de gestação mais altas do que os animais sincronizados, além de diminuir o custo com aplicação de hormônios (Gonçalves et al., 2008). Nesse contexto, são realizados diversos estudos sobre criopreservação para o estabelecimento de protocolos eficientes em manter a viabilidade celular. Um protocolo de criopreservação ideal visa atingir temperaturas criogênicas sem danos químicos e sem formação de gelo intracelular (Carvalho et al., 2011).

A vitrificação é a técnica de criopreservação cujos resultados são os mais consistentes em embriões PIVE, pois as altas velocidades de resfriamento e o tempo reduzido de exposição das células embrionárias a temperaturas críticas e aos efeitos tóxicos dos crioprotetores minimizam os danos à membrana das células embrionárias (Dinnyes et al., 2000; Mezzalira e Vieira, 2006; Gonçalves et al., 2008).

Uma estratégia para se obterem embriões bovinos produzidos in vitro de melhor qualidade e aumentar a sobrevivência deles pósdescongelamento seria a adição do ácido linoleico conjugado trans-10, cis-12 (CLA) no meio de cultura. O CLA é um ácido graxo poliinsaturado natural que apresenta atividade antiarterosclerótica, antiobesidade e inibidora da expressão de genes codificadores da produção de enzimas que estimulam a síntese de lipídeos nos adipócitos (Mitchell e McLeod, 2008). Acreditase que a suplementação de meios de cultivo in vitro com esse composto promova modificações na membrana do tecido adiposo e altere a expressão de genes relacionados com a adipogênese, diminuindo a deposição de gordura intracelular nos embriões e, assim, podendo apresentar efeitos positivos na criopreservação de embriões bovinos (Hochi et al., 1999; Pereira et al., 2007; Pereira et al., 2008; Rahme, 2012).

Considerando-se a importância de fêmeas mestiças F1 HZ para a produção leiteira no Brasil e as inconsistências existentes na técnica de criopreservação de embriões bovinos produzidos in vitro, foi avaliado o efeito da adição do CLA no meio de cultivo in vitro como estratégia para diminuir a quantidade de gotículas intracelulares de gordura depositadas nos embriões, de modo a melhorar sua congelabilidade pelo processo de vitrificação.

\section{MATERIAL E MÉTODOS}

O estudo foi desenvolvido no Laboratório de Fecundação In Vitro de Embriões do EVUFMG, durante o período de outubro de 2012 a abril de 2014. Todos os procedimentos adotados foram aprovados pela Comissão de Ética no Uso de Animais da UFMG (Protocolo $n^{\circ}$ 134/2012). Todos os reagentes utilizados no trabalho foram adquiridos da Sigma Chemical Co. (St. Louis, MO, EUA), exceto quando explicitado.

Os embriões foram produzidos de oócitos de ovários de fêmeas Nelore, obtidos em matadouro, transportados até o laboratório em solução fisiológica $(0,9 \%$ de $\mathrm{NaCl})$ aquecida a $35^{\circ} \mathrm{C}$, em tempo não superior a quatro horas após o término do abate. Os folículos com diâmetro 
entre 2 e $8 \mathrm{~mm}$ foram puncionados com o auxílio de seringa e agulha descartáveis; em seguida, os complexos cumulus-oophorus (CCOs) aspirados foram classificados de acordo com a qualidade do citoplasma e o número de camadas de células do cumulus (Constantinescu e Schatten, 2007). Os CCOs de graus I e II selecionados foram divididos aleatoriamente em três grupos e, sequencialmente, foram submetidos à maturação in vitro (MIV) por 24 horas, em estufa incubadora a $38,5^{\circ} \mathrm{C}$, com $5 \%$ de $\mathrm{CO} 2$ em ar atmosférico, 95\% de umidade em meio base de TCM-199 bicarbonato (Gibco Life Technologies, Grand Island, EUA), acrescido de $10 \%$ de SFB, $0,5 \mu \mathrm{g} / \mathrm{mL}$ de FSH (Folltropin-V®, Bioniche Inc, Canadá), $5 \mathrm{~g} / \mathrm{mL}$ de LH (Lutropin-V®, Bioniche Inc., Canadá), $10 \mu \mathrm{g} / \mathrm{mL}$ de estradiol, $22 \mu \mathrm{g} / \mathrm{mL}$ de piruvato e $83,4 \mu \mathrm{g} / \mathrm{mL}$ de amicacina. Para a fecundação in vitro (FIV), utilizou-se sêmen de touro da raça Holandesa sexado para fêmea, previamente avaliado quanto à fertilidade em sistemas de produção in vitro. Foi utilizado apenas um touro e uma partida de sêmen durante todo o experimento. A seleção de espermatozoides viáveis para a FIV foi realizada utilizando-se o método do gradiente descontínuo de Percoll. O pellet resultante da centrifugação foi lavado em meio de capacitação espermática (TALP-SÊMEN), e a concentração foi ajustada para $0,3 \times 10^{6}$ espermatozoides $/ \mathrm{mL}$ (Xu et al., 2006). O meio de FIV utilizado foi constituído por FERT-TALP (Parrish et al., 1995), suplementado com amicacina $(83,4 \mu \mathrm{g} / \mathrm{mL})$, penicilamina $(27 \mu \mathrm{g} / \mathrm{mL})$, hipotaurina $(1 \mu \mathrm{g} / \mathrm{mL})$, epinefrina $(0,3 \mu \mathrm{g} / \mathrm{mL})$, albumina sérica bovina $(5 \mu \mathrm{g} / \mathrm{mL})$, piruvato $(22 \mu \mathrm{g} / \mathrm{mL})$ e heparina $(10 \mu \mathrm{g} / \mathrm{mL})$. Os CCOs foram fecundados e incubados nas mesmas condições da MIV, por um período de 18 a 22 horas, sendo o dia da fecundação considerado o D0. Os meios de maturação e fecundação não diferiam entre os grupos experimentais, somente os meios de cultivo apresentavam diferença de composição entre os tratamentos.

Após a FIV, os zigotos foram debridados das células do CCOs, utilizando-se micropipeta automática e, posteriormente, estes foram submetidos ao cultivo in vitro (CIV), em três tratamentos: meio Synthetic Oviduct Fluid Medium (SOF) suplementado com 0,5\% de albumina sérica bovina (BSA) e $2,5 \%$ de soro fetal bovino (SFB; grupo controle) $(n=340)$; meio SOF suplementado com $0,5 \%$ de BSA, $2,5 \%$ de SFB e $100 \mu \mathrm{M}$ de ácido linoleico conjugado (CLA; grupo SFB+CLA) $(n=359)$; meio SOF contendo $0,5 \%$ de BSA, $100 \mu \mathrm{M}$ de CLA e sem SFB (grupo CLA) $(n=339)$. No D2 foi avaliada a taxa de clivagem. No D7 foi avaliada a produção de blastocistos de cada tratamento, e todos os embriões produzidos foram vitrificados pelo método de Open Pulled Straw (OPS) e armazenados em nitrogênio líquido a $-196^{\circ} \mathrm{C}$, por no mínimo duas semanas, de acordo com cada tratamento.

Os embriões selecionados para vitrificação foram lavados em solução DPBS acrescida de 5\% de SFB (Holding Medium - HM) e, então, desidratados por um minuto, em solução de $10 \%$ de etilenoglicol e $10 \%$ de DMSO em HM. Posteriormente, os embriões foram desidratados novamente em uma segunda solução contendo $20 \%$ de etilenoglicol e $20 \%$ de DMSO, por 20 segundos, e envasados em OPS (Vajta et al., 1996).

Após a vitrificação, 45 blastocistos (15 blastocistos de cada grupo experimental) foram fixados para posterior quantificação do conteúdo lipídico por coloração com Sudan Black B (Merck Ag Darmstadt, Alemanha), conforme descrito por Sudano et al. (2012), o que está demonstrado na Fig. 1.

Setenta e quatro blastocistos (sendo controle = $28, \mathrm{SFB}+\mathrm{CLA}=29$ e $\mathrm{CLA}=17$ ) foram desvitrificados e cultivados em estufa incubadora a $38,5^{\circ} \mathrm{C}$, com $5 \%$ de $\mathrm{CO} 2$ e $95 \%$ de umidade, para avaliação do desenvolvimento embrionário in vitro, observando-se a reexpansão e a eclosão dos embriões 24, 48 e 72 horas após o início do cultivo. Setenta e um blastocistos (sendo controle $=23, \mathrm{SFB}+\mathrm{CLA}=20$ e $\mathrm{CLA}=28$ ) foram transferidos para fêmeas receptoras de embrião para avaliação do desenvolvimento embrionário in vitro por meio da taxa de gestação. Foram realizadas transferências de um ou dois embriões por receptora para avaliação da sobrevivência in vivo: T1 [receptoras que receberam um blastocisto $(n=17$ embriões, sendo controle $=5$, $\mathrm{SFB}+\mathrm{CLA}=6$ e CLA $=6)$ ]; T2 [receptoras que receberam dois blastocistos, $(n=54$ embriões, sendo controle $=18, \mathrm{SFB}+\mathrm{CLA}=14$ e $\mathrm{CLA}=$ 22)]. 

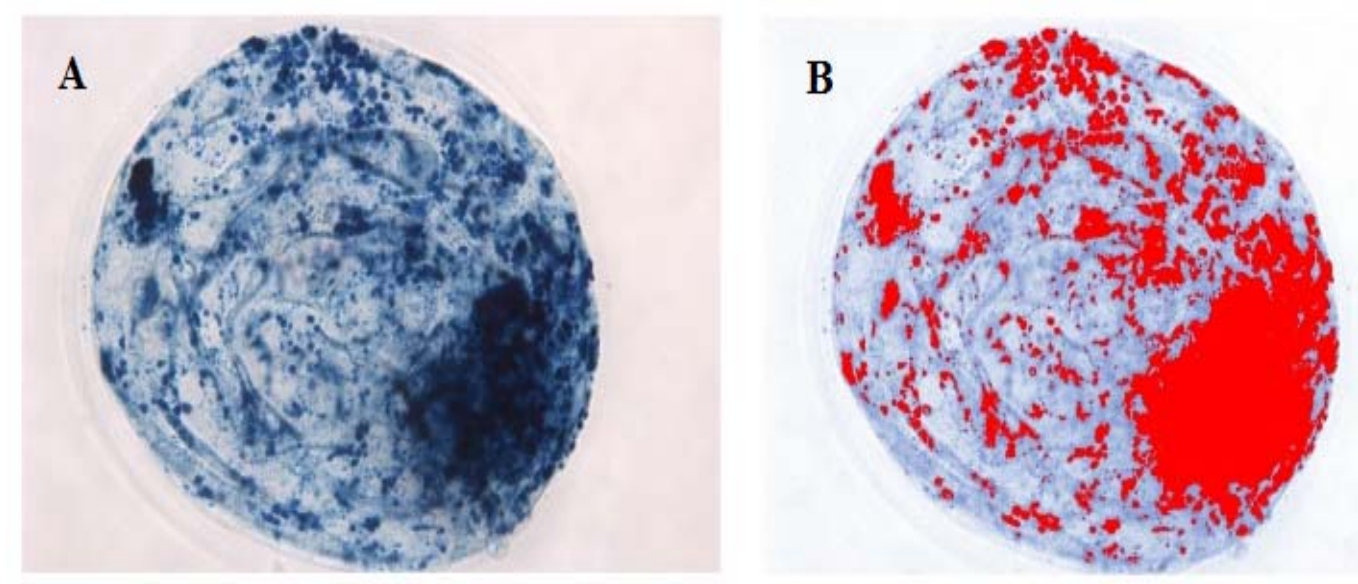

Figura 1: Quantificação lipídica de embriões bovinos por coloração com Sudan Black B. Imagem obtida por microscópio óptico com objetiva de 40x. (A) Embrião corado por Sudan Black B. (B) Conversão color-threshold para quantificação da área ocupada pelas gotículas lipídicas por meio do software Image $J$ (Wayne Rasband, National Institutes of Health, Bethesda, MD, EUA).

O experimento seguiu um delineamento inteiramente ao acaso. Os grupos de oócitos foram considerados as unidades experimentais. Os resultados de taxas de clivagem e blastocisto, segundo rotina laboratorial, foram considerados como réplicas, enquanto o teor de lipídeos foi analisado para cada embrião separadamente. Os dados foram submetidos aos testes de Kolmogorov-Smirnov e Cochran e Barttlet para verificação de normalidade e homocedasticidade, respectivamente, antes de serem submetidos à análise de variância, utilizando-se o nível de significância de 5\%. O programa de estatística utilizado para comparação dos resultados obtidos no presente trabalho foi o GraphPad Instat. Para os resultados de embriões clivados, produção de embriões em relação ao total de clivados e produção de embriões em relação ao total de oócitos inseminados, foi utilizado o teste de Tukey. Para avaliação da viabilidade embrionária in vitro, a reexpansão e a eclosão, foi realizada análise contingência pelos testes exato de Fisher ou qui-quadrado, de acordo com o tamanho dos grupos amostrais (T1 vs. T2/ T1 vs. T3/ T2 vs. T3). Os resultados da análise lipídica foram analisados pelo teste de Student-Newman-Keuls (SNK) para verificar se houve diferença entre a área ocupada pelas gotículas lipídicas coradas pelo Sudan Black $B$ entre os grupos experimentais.

\section{RESULTADOS E DISCUSSÃO}

A presença ou a ausência do soro fetal bovino e/ou do ácido linoleico conjugado trans-10, cis12 (CLA) no meio de cultivo de embriões não interferiu na clivagem embrionária (Tab. 1). O mesmo fato ocorreu com a taxa de produção de blastocistos avaliada no sétimo dia de cultivo embrionário (D7), a qual não diferiu entre os grupos experimentais (Tab. 1).

Tabela 1. Taxa de clivagem embrionária, taxa de produção de blastocistos em relação ao número de embriões clivados e taxa de produção de blastocistos em relação ao total de oócitos inseminados, de acordo com cada grupo experimental.

\begin{tabular}{ccccc} 
Tratamento & $\begin{array}{c}\text { Número de } \\
\text { oócitos } \\
\text { inseminados }\end{array}$ & $\begin{array}{c}\text { Taxa de } \\
\text { clivagem } \\
n(\%)\end{array}$ & $\begin{array}{c}\text { Taxa produção } \\
\text { embrião/clivados } \\
n(\%)\end{array}$ & $\begin{array}{c}\text { Taxa produção } \\
\text { embrião/total } \\
n(\%)\end{array}$ \\
\hline Controle & 340 & $211(62,1 \%)$ & $126(59,7 \%)$ & $126(37,1 \%)$ \\
SFB + CLA & 359 & $266(74,0 \%)$ & $127(47,7 \%)$ & $127(35,4 \%)$ \\
CLA & 339 & $251(74,0 \%)$ & $96(38,3 \%)$ & $96(28,3 \%)$ \\
\hline
\end{tabular}

Percentual médio de clivagem, produção de embriões/clivados e produção de embrião/total $(\mathrm{P}>0,05)$. 
Efeito da adição...

Pereira et al. (2008) e Marinho (2010) demonstraram que a adição do CLA trans-10, cis-12 ao meio de cultura não afetou a taxa de clivagem e a qualidade ou o desenvolvimento para o estádio de blastocisto, assim como foi encontrado no presente estudo. Com base nesses resultados, pode-se confirmar que é possível alcançar boas taxas de produção in vitro de embriões utilizando-se meios de cultivo que não contenham soro fetal bovino, sem prejuízo à taxa de produção de blastocistos.

Em relação à taxa de clivagem na presença ou ausência de SFB e em meios contendo ou não $100 \mu \mathrm{M}$ de CLA trans-10, cis-12, Pereira et al. (2008) e Marinho (2010) também encontraram taxas de clivagem média próximas a $70 \%$; já Rahme (2012) encontrou taxas de clivagem ligeiramente inferiores, de $46 \%$ e $51,9 \%$, sendo utilizado nesses trabalhos sêmen convencional. Marinho (2010) encontrou taxa de clivagem de $74 \%$ para embriões cultivados em meio contendo $100 \mu \mathrm{M}$ de CLA e clivagem superior (79\%) para embriões cultivados em $50 \mu \mathrm{M}$ de CLA. Porém, em relação à taxa de produção de blastocistos, a concentração de $100 \mu \mathrm{M}$ de CLA foi superior. Esse atraso na clivagem de embriões cultivados na ausência de SFB ocorre porque o SFB acelera o desenvolvimento embrionário (Abe e Hoshi, 2003).

Rahme (2012) encontrou 24,2\% de taxa de produção de blastocisto em relação aos clivados para o grupo com SFB e o grupo com SFB acrescido de CLA. Já para o grupo sem SFB acrescido de CLA, verificou taxa de 15\%, indicando sua menor eficiência na produção in vitro de embriões $(\mathrm{P}<0,05)$. Pereira et al. (2008) não observou prejuízos à produção de embriões em meio de cultivo suplementado com CLA e sem SFB $(23,2 \% \pm 1,3)$ em relação à produção de embriões convencional com SFB $(22,9 \% \pm$ $1,5)$, porém, comparando-se as taxas encontradas com as de Pereira et al. (2008), entre grupos experimentais semelhantes, as taxas de produção de blastocistos deste estudo, para todos os grupos experimentais, foram superiores, pois, no trabalho comparativo, os embriões foram criopreservados e biopsados.

O conteúdo lipídico intracitoplasmático nos blastômeros embrionários, para os diferentes grupos experimentais, foi avaliado na área ocupada por gotas lipídicas marcadas pelo corante Sudan Black B dos blastocistos submetidos à coloração. Houve diminuição de gotículas lipídicas nos embriões cultivados em meio suplementado com CLA em relação aos embriões cultivados na presença do SFB e na ausência do CLA $(\mathrm{P}<0,05)$. $\mathrm{O}$ grupo CLA apresentou menor área corada, representada por $272.554,5$ pixels, referente a $22 \%$ da área dos embriões submetidos à coloração. $\mathrm{O}$ grupo SFB+CLA apresentou área média ocupada pelos lipídeos corados de 301.960,7 pixels, referente a $26,7 \%$ da área total dos blastocistos desse grupo. Finalmente, o teor lipídico foi superior no grupo com SBF e sem CLA comparado aos demais grupos experimentais $(\mathrm{P}<0,05)$, apresentando área média de lipídeos de $413.124,9$ pixels, correspondente à ocupação de $29,6 \%$ da área média dos blastocistos desse grupo.

Resultados semelhantes foram encontrados por Batista (2009) e Rahme (2012), que reportaram redução significativa na quantidade de lipídeos em embriões cultivados em meio acrescido de SFB e CLA. Segundo Pereira et al. (2007), a presença de CLA no meio de cultivo embrionário leva à redução na expressão de enzimas que participam da síntese de ácidos graxos, como o acilglicerol 3-fosfato aciltransferase responsável por catalisar a síntese de triglicérides, resultando, consequentemente, em redução da deposição lipídica nas células embrionárias.

As taxas de reexpansão e de eclosão foram inferiores nos grupos contendo CLA e $\mathrm{CLA}+\mathrm{SFB}$, comparadas às do grupo controle (Tab. 2). Também trabalhando com o CLA, Pereira et al. (2008) obtiveram taxa de reexpansão de $77,5 \%$ e Rahme (2012) encontrou taxa de 64,6\% para embriões cultivados com SFB + CLA. Rahme (2012) obteve taxa de reexpansão de $71,8 \%$ em meio contendo somente o CLA. Em relação à taxa de eclosão em meio de cultivo com SFB + CLA, Pereira et al. (2008) e Rahme (2012) obtiveram, respectivamente, 60\% e $86 \%$. Rahme (2012) obteve taxa de eclosão de $56,2 \%$ em meio contendo somente o CLA.

De maneira semelhante ao encontrado no presente estudo, Batista et al. (2014) encontraram taxas de eclosão inferiores aos de Pereira et al. (2008) e Rahme (2012). No presente trabalho, foram observados $14 \%$ de eclosão para o grupo controle e $16,5 \%$ para o grupo de embriões cultivados com SFB e CLA. 
Diante desse resultado, foi apresentada a hipótese de que a suplementação do meio de cultivo com o CLA pode ter afetado os mecanismos associados com a digestão enzimática da zona pelúcida pelo trofoblasto, prejudicando a capacidade de eclosão do embrião.

Vajta et al. (1996), mediante a utilização do método de Open Pulled Straw (OPS) para vitrificação de embriões, obtiveram taxas de reexpansão variando entre 81 e $92 \%$ e taxa de eclosão entre 50 e $75 \%$, demonstrando que o método é eficiente para vitrificar embriões produzidos em condições convencionais e que, portanto, os resultados encontrados para sobrevivência embrionária pós-desvitrificação não estão ligados à técnica de criopreservação utilizada no trabalho.

Tabela 2. Taxas de reexpansão e eclosão dos embriões bovinos produzidos in vitro e submetidos à vitrificação no sétimo dia de cultivo, de acordo com o grupo experimental

\begin{tabular}{cccc}
\hline \multirow{2}{*}{ Tratamento } & $\begin{array}{c}\mathrm{N}^{\mathrm{o}} \text { de embriões } \\
\text { reaquecidos }\end{array}$ & $\begin{array}{c}\text { Taxas de reexpansão } \\
n(\%)\end{array}$ & $\begin{array}{c}\text { Taxas de eclosão } \\
n(\%)\end{array}$ \\
\hline Controle & $n$ & $19(70,4 \%) \mathrm{A}$ & $8(42,1 \%)$ \\
SFB + CLA & 27 & $13(43,3 \%) \mathrm{C}$ & $3(23,1 \%)$ \\
CLA & 30 & $8(47,1 \%) \mathrm{B}$ & $2(25,0 \%)$ \\
\hline
\end{tabular}

Médias seguidas de letras distintas, na mesma coluna, diferem entre si pelo teste qui-Quadrado ou pelo teste exato de Fisher $(\mathrm{P}<0,05)$.

Uma possível explicação para que a diminuição da deposição lipídica nos blastômeros não tenha sido referendada pelas taxas de reexpansão e eclosão embrionárias é que o cultivo in vitro com altas concentrações de CLA, durante longos períodos, pode ser prejudicial ao desenvolvimento embrionário (Absalón-Medina et al., 2014). Possivelmente, a concentração de $15 \mu \mathrm{M}$ do CLA trans-10, cis-12 ou a suplementação do meio de cultivo com isômeros do ácido linoleico conjugado 36 horas antes da vitrificação tenha resultados mais promissores (Absalón-Medina et al., 2014).

Pereira et al. (2007) encontraram taxas satisfatórias de reexpansão $(84,7 \% \pm 4,1)$ e eclosão $(63,7 \% \pm 4,1)$ pós-descongelamento de embriões cultivados com CLA. Esses resultados foram decorrentes da renovação diária do meio de cultivo e da adição do antioxidante glutationa para mitigar os danos causados pelo estresse oxidativo resultante da peroxidação de lipídeos intracitoplasmáticos.

Tabela 3. Taxas de reexpansão e eclosão de embriões bovinos em 24,48 e 72 horas de cultivo pósdesvitrificação, de acordo com o grupo experimental

\begin{tabular}{ccccccc} 
& \multicolumn{2}{c}{ 24 horas } & \multicolumn{2}{c}{48 horas } & \multicolumn{2}{c}{72 horas } \\
\cline { 2 - 7 } Tratamento & $\begin{array}{c}\text { Reexpansão } \\
(\mathrm{n} / \text { total })\end{array}$ & $\begin{array}{c}\text { Eclosão } \\
(\mathrm{n} / \text { total })\end{array}$ & $\begin{array}{c}\text { Reexpansão } \\
(\mathrm{n} / \text { total })\end{array}$ & $\begin{array}{c}\text { Eclosão } \\
(\mathrm{n} / \text { total })\end{array}$ & $\begin{array}{c}\text { Reexpansão } \\
(\mathrm{n} / \text { total })\end{array}$ & $\begin{array}{c}\text { Eclosão } \\
(\mathrm{n} / \text { total })\end{array}$ \\
\hline Controle & $73,7 \%(14 / 19) \mathrm{B}$ & $37,5 \% 3 / 8) \mathrm{B}$ & $26,3 \%(5 / 19) \mathrm{B}$ & $62,5 \%(5 / 8) \mathrm{B}$ & $0,0 \%(0 / 19)$ & $0,0 \%(0 / 8)$ \\
SFB + CLA & $100,0 \%(13 / 13) \mathrm{A}$ & $100,0 \%(3 / 3) \mathrm{A}$ & $0,0 \%(0 / 13) \mathrm{A}$ & $0,0 \%(0 / 3) \mathrm{A}$ & $0,0 \%(0 / 13)$ & $0,0 \%(0 / 3)$ \\
CLA & $100,0 \%(8 / 8) \mathrm{A}$ & $100,0 \%(2 / 2) \mathrm{A}$ & $0,0 \%(0 / 8) \mathrm{A}$ & $0,0 \%(0 / 2) \mathrm{A}$ & $0,0 \%(0 / 8)$ & $0,0 \%(0 / 2)$ \\
\hline
\end{tabular}

Cultivo pós-desvitrificação de embriões bovinos produzidos em meio suplementado ou não com soro fetal bovino (SFB) e ácido linoleico conjugado (CLA). Médias seguidas de letras distintas, na mesma coluna, diferem entre si pelo teste exato de Fisher $(\mathrm{P}<0,05)$.

Diferentemente do esperado, os embriões do grupo controle evoluíram mais lentamente do que os embriões dos demais tratamentos (Tab. 3). Segundo Abe e Hoshi (2003), a presença do SFB nos meios de cultivo in vitro acelera o desenvolvimento embrionário. Reiterando os resultados anteriores, Marinho (2010) encontrou que a ausência do SFB nos meios de cultivo in vitro atrasa a clivagem embrionária, haja vista que fornece fatores de crescimento, hormônios, 
nutrientes e componentes antioxidantes, aumentando a produção de embriões e acelerando a desenvolvimento embrionário (Abe e Hoshi, 2003).

Na avaliação da sobrevivência embrionária após a transferência para receptoras de embrião, apenas uma gestação foi verificada nos diagnósticos precoce e confirmatório, resultado da transferência de um embrião do grupo controle. As taxas de gestação para os grupos controle, SFB+CLA e CLA foram, respectivamente, de 4,35\% (1/23), 0\% (0/20) e $0 \%(0 / 28)$. Novas transferências embrionárias deverão ser realizadas para se avaliar o efeito do CLA na sobrevivência embrionária in vivo, referendando a taxa de reexpansão e de eclosão in vitro.

\section{CONCLUSÕES}

A adição do ácido linoleico conjugado em meios de cultivo in vitro, na presença ou não do soro fetal bovino, não reduziu a produção de blastocistos, sendo possível conseguir taxas de clivagem e produção de embrionárias semelhantes a meios que não contêm esse composto. $\mathrm{O}$ isômero do ácido linoleico conjugado trans-10, cis-12 foi eficaz em reduzir a deposição de lipídeos intracitoplasmáticos nas células embrionárias, porém não houve diferença de viabilidade após a desvitrificação dos embriões. Possivelmente, modificações na dose e no momento de administração do CLA ou a associação do CLA com substâncias que aumentam a produção de antioxidantes poderão incrementar os resultados de sobrevivência embrionária obtidos neste trabalho.

\section{AGRADECIMENTOS}

À Fapemig (Projeto CVZ APQ 0912-12), ao CNPq (Projeto 484602/2012-8) e à Capes, pelo apoio financeiro; ao Cenatte Embriões, pelo fornecimento dos meios e pelo suporte técnico; à Epamig, pela parceria.

\section{REFERÊNCIAS}

ABE, H.; HOSHI, H. Evaluation of bovine embryos produced in high performance serumfree media. J. Reprod. Dev., v.49, p.193-202, 2003.
ABSALÓN-MEDINA, V.A.; BEDFORDGAUS, S.J.; GILBERT, R.O. et al. The effects of conjugated linoleic acid isomers cis-9, trans11 and trans-10, cis-12 on in vitro bovine embryo production and cryopreservation. $J$. Dairy Sci., v.97, p.6164-6176, 2014.

BATISTA, R.I.T.P. Efeito do ácido linoléico conjugado trans-10, cis-12 na regulação do acúmulo de lipídeos e expressão gênica de embriões produzidos in vitro. 2009. Dissertação (Mestrado) - Escola de Ciências Biológicas da Universidade Federal de Juiz de Fora, Juiz de Fora, MG.

BATISTA, R.I.T.P.; RAPOSO, N.R.B.; CAMPOS-JÚNIOR, P.H.A. et al. Trans-10, cis12 conjugated linoleic acid reduces neutral lipid contente and may affect cryotolerance of in vitro-produced crossbred bovine embryos. $J$. Anim. Sci. Biotecnol., v.5, p.1-8, 2014.

CARVALHO, A.A.; FAUSTINO, L.R.; FIGUEIREDO, J.R. et al. Vitrificação: uma alternativa para a preservação de embriões e material genético de fêmeas mamíferas em criobancos. Acta Vet. Bras., v.5, p.236-248, 2011.

CONSTANTINESCU, G.M.; SCHATTEN, H. Comparative reproductive biology. Carlton: Blackwell Publishing, 2007. 402p.

DINNYES, A.; DAI, Y.; JIANG, S. et al. High developmental rates of vitrified bovine oocytes following parthenogenetic activation, in vitro fertilization, and somatic cell nuclear transfer. Biol. Reprod., v.63, p.513-518, 2000.

GONÇALVES, P.B.D.; VISITIN, J.A.; OLIVEIRA, M.A.L. et al. Produção in vitro de embriões. Biotécnicas aplicadas à reprodução animal. São Paulo: Rocca, 2008. p.261-301.

HOCHI, S.; KIMURA, K.; HANADA, A. Effect os linoleic acid-albumin in the culture medium on freezing sensitivity of in vitro-produced bovine morulae. Theriogenology, v.52, p.497504, 1999.

MARINHO, L.S.R. Ácido linoleico conjugado na criotolerância de embriões bovinos produzidos in vitro. 2010. 76f. Dissertação (Mestrado em Ciência Animal) - Universidade do Estado de Santa Catarina, SC. 
MEZZALIRA, A.; VIEIRA, A.D. Cryopreservation of cows oocytes and embryos. Acta Sci.. Vet., v.34, p.191-196, 2006.

MITCHELL, P.L.; McLEOD, R.S. Conjugated linoleic acid and atherosclerosis: studies in animal models. Biochem. Cell Biol., v.86, p.293$301,2008$.

PARRISH, J.J.; KROGRNAES, A.; SUSKOPARRISH, J.L. Effect of bovine sperm separation by either swim-up and percoll method on success of "in vitro" fertilization and early embryonic development. Theriogenology, v.44, p.859-869, 1995.

PEREIRA, R.M.; BAPTISTA, M.C.; VASQUES, M.I. et al. Cryosurvival of bovine blastocists is enhanced by culture with trans-10 cis-12 conjugated linoleic acid (10t,12c CLA). Anim. Reprod. Sci., v.98, p.293-301, 2007.

PEREIRA, R.M.; CARVALHAIS, I.; PIMENTA, J. et al. Biopsed and vitrified bovine embryos viability is improved by tras 10 , cis 12 conjugated linoleic aid supplementatios during in vitro embryo culture. Anim. Reprod. Sci., v.106, p.322-332, 2008.
RAHME, L.S.T.R. Efeito do ácido linoléico conjugado na sobrevivência pós criopreservação de embriões bovinos produzidos in vitro. 2012. 42f. Dissertação (Mestrado em Ciência Animal). - Escola de Veterinária, Universidade Federal de Minas Gerais, MG.

SUDANO, M.J.; SANTOS, V.G.; TATA, A. et al. Phosphatidylcholine and sphingomyelin profiles vary in bos taurus indicus and bos taurus taurus in vitro- and in vivo-produced blastocysts. Biol. Reprod., v.87, p.1-11, 2012.

VAJTA, G.; HOLM, P.; GREVE, T. et al. Overall efficiency of in vitro embryo production and vitrification in cattle. Theriogenology, v.45, p.683-689, 1996.

XU, J.; GUO, Z.; SU, L. et al. Developmental potential of vitrified Holstein cattle embryos fertilized in vitro with sex-sorted sperm. J. Dairy Sci., v.89, p.2510-2518, 2006. 